\title{
Representaciones sociales frente al proyecto de carrera profesional docente en Chile: análisis estructural del discurso
}

Carmen Gloria Jarpa Arriagada' (D) María Teresa Castañeda Díaz' (1)

\section{RESUMEN}

Los procesos socio-políticos en educación afectan al gremio docente. El objetivo del artículo es analizar las representaciones sociales de los profesores y otros actores relevantes frente al Proyecto de Ley de Desarrollo Profesional Docente. La estrategia metodológica fue análisis estructural del discurso de registros publicados entre marzo y junio de 2015. Los hallazgos develan representaciones sociales que demandan mayor participación en la construcción del proyecto; cuestionan el enfoque de evaluación docente basado en la rendición de cuentas; sostienen que el proyecto intensificará la despedagogización, desprofesionalización y pauperización de las condiciones laborales y creen necesario regular la formación inicial y continua de los profesores. En suma, los profesores rechazan la iniciativa por considerarla no representativa, basada en la desconfianza y validando un sistema de evaluación punitivo que los invisibiliza como actor relevante en el diseño del mencionado proyecto de ley.

PALABRAS CLAVE

reforma educacional; política educacional; condiciones de trabajo.

'Universidad del Bío-Bío, Región del Biobío, Chile. 


\title{
TEACHERS' SOCIAL REPRESENTATIONS CONCERNING THE PROJECT FOR CAREER IN PROFESSIONAL TEACHING IN CHILE. STRUCTURAL DISCOURSE ANALYSIS
}

\begin{abstract}
The socio-political processes in education affect the teaching profession. The objective of the article is to analyze the social representations of teachers and other relevant actors in relation to the Project of Professional Teacher Development Law. The methodological strategy was the structural analysis of the discourse published between March and June 2015. The findings reveal social representations that demand greater participation in the construction of the project; challenge the accountability-based approach to teacher assessment; argue that the project will intensify the dismissal, deprofessionalization and impoverishment of working conditions and believe that it is necessary to regulate the initial and continuous training of teachers. In sum, teachers reject the initiative as non-representative, based on mistrust and validating a punitive evaluation system that makes them invisible as a relevant actor in the design of the aforementioned bill.
\end{abstract}

\section{KEYWORDS}

educational reform; educational policy; working conditions.

\section{REPRESENTAÇÕES SOCIAIS PERANTE O PROJETO DE CARREIRA DOCENTE NO CHILE: ANÁLISE ESTRUTURAL DO DISCURSO}

\section{RESUMO}

Os processos sociopolíticos na educação afetam a profissão docente. $\mathrm{O}$ objetivo deste artigo é analisar as representações sociais de professores e de outros atores relevantes em relação ao Projeto de Lei de Desenvolvimento Profissional de Professores. A estratégia metodológica utilizada foi a análise estrutural do discurso de registros publicados entre março e junho de 2015. Os achados revelam representações sociais que exigem maior participação na construção do projeto; questionam o enfoque de avaliação docente baseada na prestação de contas; alegam que o projeto intensificará a demissão, a desprofissionalização e a pauperização das condições de trabalho. Acreditam, dessa maneira, que é necessário regulamentar a formação inicial e continuada dos professores. Em suma, os professores rejeitam a iniciativa como não representativa, baseada na desconfiança e na validação de um sistema de avaliação punitivo, que os torna invisíveis como atores importantes no projeto da referida lei.

PALAVRAS-CHAVES

reforma educacional; política educacional; condições de trabalho. 


\section{INTRODUCCIÓN}

Este artículo aborda el rechazo que el Proyecto de Ley de Desarrollo Profesional Docente ha recibido de parte de los profesores y también de otros actores sociales. Nuestro propósito fue identificar en la estructura del discurso textual tanto códigos y patrones repetitivos, como relaciones y valorizaciones contenidas en la narrativa dominante expuesta en las publicaciones de medios de comunicación nacional.

Como contexto del presente artículo, es preciso señalar que el proyecto de ley fue ingresado al Congreso Nacional para tramitación el 20 de abril de 2015. Tiene tres objetivos generales, uno de los cuales es "Fortalecer el desarrollo profesional docente para promover el avance en la carrera profesional" (Chile, 2015, p. 7). Este objetivo declara la instalación de un sistema de desarrollo profesional docente que establece una trayectoria asociada a la experiencia y al desempeño. Se ofrece una carrera estructurada en cinco tramos. El ascenso en la carrera requerirá la correspondiente certificación de tramo, la que se obtiene aprobando una prueba de conocimientos disciplinares y un portafolio. El paso de un tramo a otro supone aumentos salariales. Finalmente, se propone modificación paulatina de la proporción de horas lectivas/no lectivas, pasando de 75/25 a 65/35 en 2018.

Para la interpretación de las representaciones sociales, adoptamos como marco conceptual lo relativo a los ciclos de las políticas educativas y su relación con la construcción de una carrera profesional docente. En este sentido, para Martinic y Elacqua (2010), la formulación de reformas educativas y su puesta en práctica se realiza en un complejo sistema de relaciones, donde una diversidad de actores interviene desde sus propios marcos referenciales. El concepto de referencial es definido como un marco interpretativo o cognitivo de los actores involucrados, que configuran formas de pensar las políticas públicas como una producción intelectual de imágenes comunes de la sociedad (Jobert y Muller, 1987). En este contexto, la política se entiende como una práctica de construcción de consensos y de sentidos compartidos, dónde tienen lugar también la incertidumbre, el disenso y la disputa de discursos y de prácticas sobre las reformas.

Para descifrar la oposición al Proyecto de Carrera Profesional Docente hemos seguido la propuesta de Grindle (2001), que plantea la definición de categorías analíticas para visibilizar la interacción dinámica entre estructura, acción y proceso. La estructura se refiere a las instituciones relativamente durables de la economía y del sistema político que condicionan y afectan la reforma. El análisis en profundidad de las estructuras y de los incentivos que ocupan las instituciones permite comprender por qué hay oposición y las reformas no avanzan. Para llevar a cabo este análisis, Grindle (2001) recurre al concepto de agencia, que alude al grado en que una acción o intervención puede producir cambios en las condiciones y en los resultados de los conflictos y oposición a las reformas.

Adicionalmente a las ideas de Grindle, también nos apoyamos en los planteamientos de Weinstein (2014), quien caracteriza el mapa de los actores principales que deberían estar presentes en "la política de las políticas docentes". Este mapa, nos sitúa en la perspectiva de reconocer a actores decisores y actores influenciadores, 
estableciendo que la generación de una política docente debería considerar a todos estos grupos de interés.

En coherencia con lo expuesto, se organiza el artículo presentando en primer lugar el marco de referencia que sustenta el análisis. Posteriormente, se describe el marco metodológico utilizado y se presentan los principales hallazgos. Para finalizar, se discuten los resultados y se presentan las conclusiones que sintetizan las representaciones sociales develadas.

\section{CICLOS DE POLITICAS EDUCATIVAS EN CHILE DESDE LA}

\section{DÉCADA DE LOS 1980 Y SU EFECTO EN LA PROFESIÓN DOCENTE}

En Chile se ha observado una creciente preocupación respecto de la calidad de la educación. Según Beca (2014), en este debate — que alcanza ya cuatro décadas - es posible distinguir tres ciclos: uno orientado al mercado como regulador de la actividad docente (década de los 1980); otro marcado por los esfuerzos de profesionalización docente (años 1990) y un último ciclo centrado en la evaluación docente entendida como control de calidad (2000 a la actualidad). En la década de los 1980, en el contexto de la dictadura militar, las políticas educativas apuntaron a la municipalización de la educación y a la instalación de principios de regulación basados en el mercado y en la competencia entre escuelas. Para Beca (2014), se instala una visión de la calidad de la educación que contribuye a la pérdida total de la autonomía profesional docente y provoca la "desvalorización de la formación docente experimentada”, originando una situación de extrema precariedad laboral.

En la década de los 1990, en el contexto de gobiernos democráticos, las políticas educativas apuntan a que el Estado recupere un rol central, basado en el control del currículo, de la pedagogía y de la evaluación de resultados (Martinic, 2010). Destacan reformas como el aumento de horas en la jornada escolar (1997); reformas al curriculum $(1996,1998)$; reformas al sistema de evaluación de los resultados de aprendizaje (1992); reformas de los sistemas de evaluación docente (1990). Según Martinic (2010), la nueva teoría de acción implementada en las reformas de los 1990, no produce transformaciones en la institucionalidad del sistema. Por un lado, se apunta a fortalecer el rol regulador del Estado y, por otro, se aprueban políticas que consolidan la regulación del mercado en la educación. Sin embargo, a pesar de sus limitaciones, para Beca (2014), estas reformas evidencian una visión inclinada a desarrollar esfuerzos de profesionalización de la docencia, teniendo como eje el Estatuto de los Profesionales de la Educación (Ministerio de Educación, 1991), cuyo propósito principal se orientaba a la mejora de las condiciones laborales de los docentes de aula.

En el contexto del tercer ciclo de políticas educativas en Chile, según Martinic (2010), el año 2006 marca el comienzo de una serie de reformas que apuntan a la consolidación de mecanismos de regulación propios de un "Estado evaluador": Ley de Subvención Educacional Preferencial (2008); Ajuste al Marco Curricular de la Enseñanza Básica y Media (2009b); Ley General de Educación (2009a); Agencia de Calidad (2011); Sistema de Aseguramiento de la Educación Básica y Media (2011); creación de la Superintendencia de Educación (2012); 
Bases Curriculares de Educación Básica (2012). En este marco, las políticas están focalizadas en los resultados y en la rendición de cuentas. Como consecuencia de este marco regulatorio, Beca (2014) constata la instalación de una idea fuerza respecto de que los factores decisivos para mejorar la profesión docente son la selección, la competencia y las evaluaciones asociadas a premios y castigos. En este contexto, "la identidad profesional del docente se encuentra fuertemente condicionada por la presión por resultados inmediatos medidos por pruebas estandarizadas, lo que lleva a procurar soluciones simplistas o justificaciones externas, más que a asumir una responsabilidad profesional"(Beca, 2014, p. 10). Esta presión se materializa en el proyecto que durante el 2015 se envía al Congreso para crear una nueva carrera profesional docente.

\section{LA IDENTIDAD DOCENTE TENSIONADA DESDE LAS POLÍTICAS PÚBLICAS}

Como efecto de los tres ciclos de las políticas ya descritas, los profesores han visto intensificadas las tareas que deben realizar y las evaluaciones del desempeño docente a las que se deben someter. El énfasis está puesto en la performatividad, es decir, se observa una fuerte tendencia a "enjuiciar el trabajo docente sobre la base de su desempeño observable, el que a su vez se restringe a los resultados de aprendizaje de los alumnos medidos a través del SIMCE” (Ávalos y Sotomayor, 2012,p. 80).

En efecto, estudios realizados en Chile con profesores de enseñanza básica y media (Ávalos y Sotomayor, 2012; Belleï y Valenzuela, 2010), concluyen que la identidad y el estatus profesional de los docentes chilenos está tensionado por las expectativas de una sociedad que ve en la educación la principal palanca para el desarrollo social y económico del país, pero que no entiende que para enfrentar sus demandas los profesores necesitan reconocimiento y apoyo. Los profesores chilenos perciben que su profesión viene perdiendo estatus, acelerada y sostenidamente, situando a la docencia en un nivel medio-bajo o bajo. Además, perciben que los actores institucionales relevantes en educación (gobierno, Colegio de Profesores, y sostenedores) contribuyen a la desvalorización de la profesión docente (Belleï y Valenzuela, 2010).

Finalmente, se observa cómo las políticas públicas en educación tensionan la identidad de los profesores con políticas de medición, incentivos y sanciones que reducen la tarea docente a la producción de resultados en pruebas estandarizadas. Así, desde la política pública, la eficiencia y efectividad del trabajo docente solo se puede inferir de los puntajes en las diversas pruebas del SIMCE (Montecinos, 2014). En este contexto, los profesores reservan el sentido amplio de su misión al reconocimiento privado que reciben de sus alumnos, de los padres, apoderados y colegas. Mientras, en lo público se someten a las demandas del sistema. Sin embargo, la dificultad para responder a estas demandas externas constituye un factor que produce conflictos de identidad profesional, afectando negativamente el grado de emotividad positiva y de compromiso de los docentes. Las condiciones difíciles de trabajo y las expresiones públicas de mensajes que desvalorizan su capacidad, a partir de resultados deficientes en mediciones de los aprendizajes estudiantiles y evaluaciones del desempeño docente, debilitan su sentido de autoeficacia (Ávalos y Sotomayor, 2012). 


\section{LA NECESIDAD DE UNA POLÍTICA EDUCATIVA}

\section{DE DESARROLLO PROFESIONAL DOCENTE EN CHILE}

La consolidación de un Estado evaluador ha incidido en la construcción de un discurso pedagógico basado en la rendición de cuentas. Según Montecinos (2014, p.290), "el fin último de un sistema de rendición de cuentas es el desarrollo de la responsabilidad con que cada profesor debe asumir su labor profesional". Sin embargo, puesto que la calidad de un sistema educativo tiene como techo las capacidades de sus actores principales: docentes, directivos y sostenedores (Vanni y Bravo, 2010, p. 203), se releva la necesidad de una política de carrera docente que garantice el desarrollo de la responsabilidad del profesor en el ejercicio de la profesión. En este marco, UNESCO (2013, p. 76) define carrera docente como "el régimen legal que establece el ejercicio de la profesión dentro de un ámbito determinado, regulando, entre otras materias, el sistema de ingreso, ejercicio, movilidad, desarrollo, ascenso y retiro de las personas que ejercen la profesión docente".

Al mismo tiempo, UNESCO (2013) ofrece orientaciones para el diseño de políticas docentes relevantes para América Latina y el Caribe, tales como:

- Fortalecimiento de la profesión docente, siendo uno de los núcleos centrales la formación inicial y continua (Barber y Mourshed, 2008; OECD, 2014a; UNESCO, 2013; Vaillant y Marcelo, 2015).

- Reconocimiento de las diferentes etapas de desarrollo en la trayectoria profesional (Day et al., 2006; Marcelo, 2010; UNESCO, 2013; Vaillant, 2009).

- Mejoramiento de remuneraciones e incentivos para estimular la labor profesional (Belleï y Valenzuela, 2010; OCDE, 2014a; UNESCO, 2013)

- Mejoramiento de las condiciones laborales del ejercicio de la profesión, tales como la proporción de horas lectivas/no lectivas y la cantidad de alumnos por curso (OECD, 2014a, 2014b, 2014c).

- Desarrollo de sistemas objetivos y justos para observar el desempeño docente (Belleï y Valenzuela, 2010; Schmelkes, 2014; UNESCO, 2013).

\section{MÉTODO}

El enfoque epistemológico del estudio se enmarca en la teoría de las representaciones sociales, en el sentido que le otorga Moscovici (1998), esto es, la representación social siempre es de un sujeto y está definida por un contenido con respecto a un objeto. De esta forma, "la representación social es tributaria de la posición que ocupan los sujetos en la sociedad, la economía, la cultura" (Jodelet, 1986, p. 475). En definitiva, entenderemos las representaciones sociales como las imágenes y los modelos explicativos que un determinado grupo social (los profesores y otros actores relevantes) posee de un fenómeno o contenido de su realidad (Proyecto de Carrera Profesional Docente) y que se constituye como una herramienta conceptual que posibilita establecer un nexo entre dichos sujetos, la cultura y la historia, es decir, entre la subjetividad y la vida social de los seres humanos (Farr, 1984; Wagner et al., 2011). 
Para aproximarnos a las representaciones sociales de los profesores, optamos por la estrategia del análisis estructural del discurso. Este método se inspira en la semántica estructural desarrollada por Greimas (1987) y propone reglas y procedimientos para definir los principios que organizan las representaciones de los sujetos sobre problemas y prácticas específicas. En consecuencia, se construyeron categorías que transformaron los datos y el texto a unidades que se relacionan, comparan y agregan a unidades mayores. Esta transformación implicó, a su vez, pasar del texto y sentido literal a categorías y relaciones subyacentes entre categorías que configuran un sentido y unas prácticas en el contexto de la actual discusión del Proyecto de Carrera Profesional Docente (Miles y Huberman, 2003).

Las fuentes elegidas para el análisis estructural fueron veinte registros con la opinión de profesores y de otros actores sociales que han hecho suyo el discurso del profesorado, acerca del Proyecto de Carrera Profesional Docente. Los criterios de selección de los documentos fueron: (i) entrevistas, notas de prensa, cartas oficiales de profesores, de la asociación gremial y de otros actores que interpretan el discurso del gremio docente; (ii) entrevistas, notas de prensa, cartas oficiales que se hayan planteado sobre el Proyecto de Carrera Profesional Docente entre enero 2015 y junio 2015. Una vez seleccionados los documentos, se procedió a su exploración siguiendo el modelo de análisis estructural (Martinic, 1992, 1998).

\section{RESULTADOS}

Los resultados se presentan agrupados en función de las principales representaciones sociales presentes en los discursos analizados.

\section{CONSTRUCCIÓN DEL PROYECTO DE CARRERA PROFESIONAL DOCENTE:}

\section{AUSENCIA DE ACTORES CLAVES Y DEMANDAS DE MAYOR PARTICIPACIÓN}

La representación social que realizan los profesores sobre la construcción del Proyecto de Carrera Profesional Docente incluye una clara asociación entre los actores sociales involucrados, el tipo de participación que éstos instalan y la legitimidad otorgada al proyecto. Esta relación es valorizada en una dimensión de opuestos, distinguiéndose una manera de construir positivamente el proyecto y una manera de construirlo negativamente.

Podemos apreciar una firme representación social anclada en la "legitimidad" del proyecto. En efecto, existe una aspiración del gremio docente de constituirse en actor clave en la construcción de un proyecto que, no solo lo afecta directamente, sino que regulará su ingreso a la carrera, medirá su desempeño y establecerá, sensiblemente, sus condiciones laborales y salariales. Si entendemos las políticas como "acciones públicas", asumimos que trascienden "lo gubernamental" e implican espacios y actores interrelacionados que coordinan sus conocimientos y acciones en función de objetivos concordados o en discusión. Desde el discurso de los profesores, se devela una aspiración legítima a una mayor participación "vinculante" del gremio docente como "grupo de interés" en el proyecto. Entonces, asistimos a un cuestionamiento de la concepción clásica de las políticas públicas que se caracterizaba por 
la presencia de un Estado centralizado, aplicando una lógica de arriba hacia abajo y desestimando la participación de otros actores sociales (Martinic y Elacqua, 2010).

En la estructura cruzada (Figura 1), se observa que los discursos recogidos oponen la concepción de un proyecto representativo (profesores como actor protagónico y con una participación vinculante) a una concepción de un proyecto ilegítimo, donde el actor protagónico es un experto tecnócrata y la participación es no vinculante. Asimismo, emerge el cuadrante que combina una participación protagónica de los profesores pero con una participación no vinculante. Por ejemplo, plantean que "efectivamente hubo un proceso de diálogo, pero ellos nunca fueron vinculantes o resolutivos, y lo que hizo el Ministerio fue siempre imponer sus puntos de vista en las mesas de trabajo y no acoger las demandas centrales del Magisterio" (Eduardo, 5/6/2015, entrevista Colegio de Profesores de Chile). Hemos denominado a esta concepción del proyecto como "espurio"ya que delata una ilusión de participación. Finalmente, emerge una posibilidad de que el proyecto considere la participación vinculante de los profesores pero que el actor protagónico sea un experto; en tal caso, el proyecto adquiere la connotación de consensuado. Al respecto, los profesores declaran que "el Proyecto de Ley de Carrera Docente no nos representa y debe ser construida con los profesores como corresponde" (Ricardo, 3/6/2015, comunicado Colegio de Profesores de Chile); "es insuficiente el proceso de participación y de discusión que ha establecido el gobierno en materia de carrera docente" (Eduardo, 14/1/2015, nota de prensa Partido Humanista de Chile).

\section{LA EVALUACIÓN DOCENTE: EL ENFOQUE DE RENDICIÓN DE CUENTAS EN ENTREDICHO}

La estructura cruzada de la Figura 2, devela como nudo crítico de la propuesta de ley lo concerniente a la certificación de la calidad docente como modelo para ascender en la carrera profesional. Los profesores advierten sobre las consecuencias negativas de este modelo de evaluación docente: consideran que se propone una

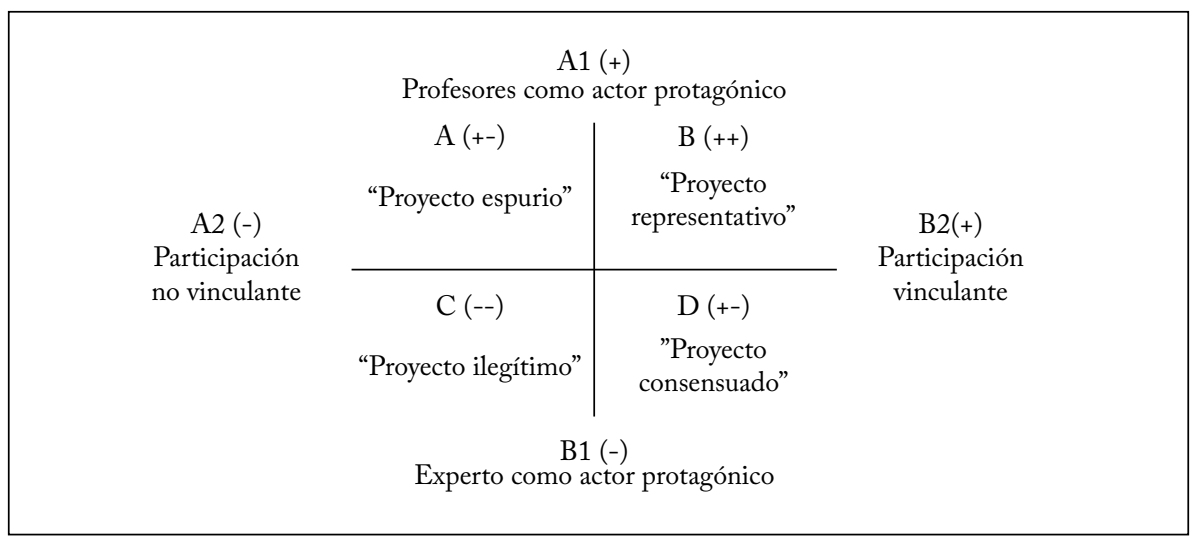

Figura 1 - Estructura cruzada.

Fonte: Base de datos de búsqueda.

Elaboración propia. 
evaluación individual, que incentiva la competencia entre colegas, que cumplirá una función de castigo o sanción al docente mal evaluado y que por tanto incentivará, mediante motivación extrínseca, la preparación para la evaluación en desmedro de la preparación de la instrucción. Como modelo de evaluación docente alternativo, los profesores se manifiestan a favor de una evaluación formativa, centrada en procesos y productos, colaborativa, cooperativa, orientada a la mejora de la práctica docente. En suma, la evaluación es entendida como un proceso sistémico, integral y formativo.

$\mathrm{El}$ análisis estructural devela un potente discurso, de valorización negativa: la evaluación docente concebida como "certificación", deriva en un sistema de múltiples evaluaciones, obligatorio, individual, externo y punitivo; genera que la rendición de cuentas sea exclusivamente la productividad; incentiva, por tanto, la motivación extrínseca del docente; debilitando la autonomía del profesor y produciendo, en definitiva, la consecuente desvalorización de la profesión docente. Algunos discursos representativos señalan "esta sofisticada versión de la lógica de 'garrote y zanahoria' es la que para el gobierno debiera ordenar la labor de los profesionales que van a educar a nuestros niñas y niños" (Gabriel, 4/6/2015, Columna de Opinión, The Clinic.cl); "Resulta evidente que si para progresar en la carrera docente el profesor debe ser bien evaluado en la certificación, su concentración y mayor dedicación estarán en aquello y no en el trabajo en aula" (Ignacio, 9/5/2015, Columna de Opinión, E1 Mostrador.cl). En suma, en esta representación advertimos dos cuestiones sustanciales: la idea subyacente de un Estado evaluador (incomprendida por el gremio docente) y la idea de que la certificación (como rendición de cuentas) contribuye a la desvalorización social de la profesión docente.

\section{CONDICIONES DE TRABAJO DE LOS PROFESORES EN CHILE:}

\section{DESPEDAGOGIZACIÓN, DESPROFESIONALIZACIÓN Y PAUPERIZACIÓN}

En la discusión del Proyecto de Carrera Profesional Docente, el discurso de los profesores ha estado colonizado por un concepto: agobio. El análisis detallado del

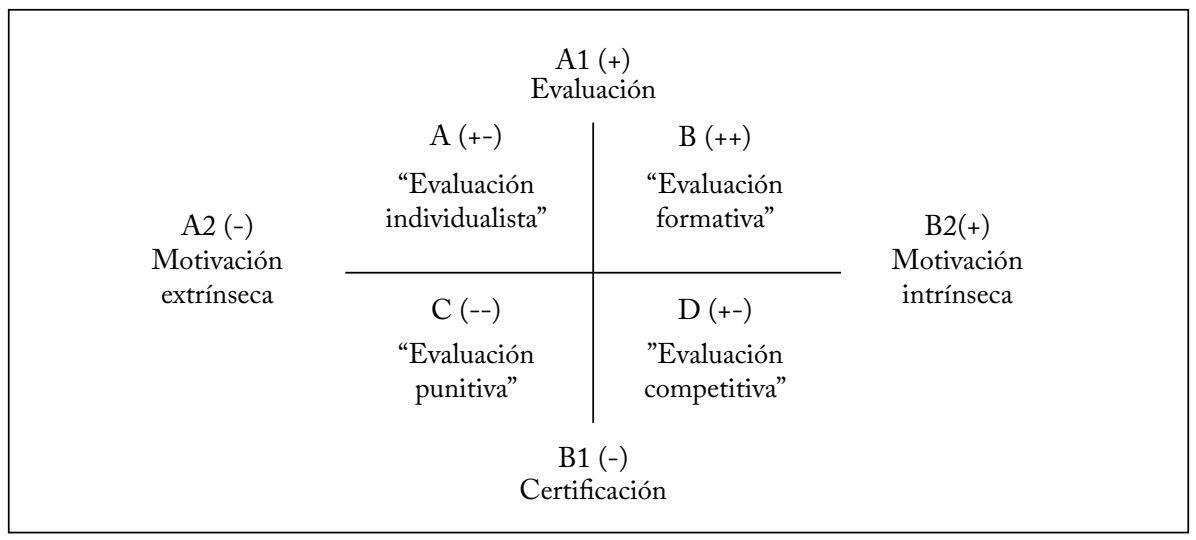

Figura 2 - Estructura cruzada.

Fonte: Base de datos de búsqueda.

Elaboración propia. 
corpus textual de los registros revisados explica el agobio laboral como un efecto de una serie de factores concatenados. Algunos discursos relevantes son "Se desconoce quizás lo más relevante: que son las condiciones laborales las que inciden de forma directa en el desempeño de los docentes y en su capacidad de generar procesos de aprendizajes profundos y pertinentes" (Pamela, 4/6/2015, Columna de Opinión, E1 Desconcierto.cl); “¿Acaso no influye en el desempeño de un niño la estabilidad laboral de sus docentes? La precarización de la labor docente, sin duda, afecta la calidad de la educación"(Jaime, 22/4/2015, Columna de Opinión , El Dínamo.cl). Las representaciones docentes aluden a que la desconfianza en el desempeño docente se expresa en medir su eficiencia y eficacia a través de la certificación obligatoria, múltiple, individual, externa y punitiva. Esta certificación sostiene un modelo de equidad externa salarial que profundizará la competitividad en el trabajo, incentivará el individualismo, provocará que las horas no lectivas (65/35) sean dedicadas a preparar las certificaciones. Todo lo anterior, incrementará el agobio laboral al cual los profesores ya están expuestos.

\section{POLITICAS NACIONALES DE FORMACIÓN INICIAL Y CONTINUA: DE LA REGULACIÓN DEL MERCADO A LA REGULACIÓN DEL ESTADO}

Aunque el Proyecto de Carrera Profesional Docente aborda solo tangencialmente la cuestión de la formación inicial, una narrativa importante rescatada de los registros revisados tiene que ver justamente con los cuestionamientos hacia la calidad de la formación, la acreditación de las carreras pedagógicas, el valor de la "credencial" como carrera acreditada y la reactualización del debate sobre la necesidad de más Estado y menos mercado. Algunos discursos significativos son "Si un título profesional entregado por una universidad reconocida por el Estado no sirve para ejercer esa profesión, ¿qué sentido tiene que el Estado reconozca ese título? El Proyecto de Carrera Docente hace responsable al profesor de la formación que recibió y no a su casa de estudios" (Gonzalo, 4/6/2015, Columna de Opinión, The Clinic. cl); "Es un proyecto basado en la desconfianza, tanto en los docentes noveles como en los docentes con experiencia y por lo tanto adolece de una política nacional de formación docente y de formación continua" (Directiva, 19/5/2015, Comunicado Colegio de Profesores de Chile).

En suma, el análisis estructural nos muestra la asociación negativa entre un Estado evaluador, la formación inicial docente regulada por el mercado y el desarrollo profesional docente como un mecanismo correctivo de las "malas prácticas" docentes. Su inverso es la presencia de un Estado garante, donde la formación inicial esté regulada y en manos del Estado y el desarrollo profesional docente se consiga en el aula, a través del ciclo de vida de un profesor.

\section{DISCUSIÓN}

Respecto de la participación en la construcción del Proyecto de Carrera Profesional Docente, advertimos que la representación social del profesorado traduce una desconexión entre la agenda política y la agenda sistémica (Marcelo, 2010). 
En este escenario, el proyecto aparece como una política regulatoria, material y simbólica (Marcelo, 2010), pero desde la representación social de los profesores emerge la aspiración de que se constituya en una política autorregulatoria y redistributiva.

Las representaciones de los profesores en relación con la evaluación docente, revelan la existencia del "Estado evaluador" en el nuevo paradigma de gobernanza (Martinic, 2010).Podemos advertir que la implementación de la evaluación docente concebida como "rendición de cuentas" es rechazada por los profesores porque ha sido instalada desde arriba hacia abajo, ha definido a un solo actor social (los profesores) para ser certificado, medido y eventualmente sancionado; los instrumentos de evaluación son estandarizados y promueven la competitividad; y la "autoridad" (Ministerio de Educación y Parlamento) que debe discutir el proyecto se encuentra en una crisis de legitimidad (Belleï y Valenzuela, 2010).

Los profesores no se oponen a la existencia de evaluación. La opinión crítica de los docentes se refiere a los mecanismos (certificación), procedimientos (pruebas estandarizadas) y funciones (certificar calidad docente). Al respecto, Schmelkes (2014) explica que los sistemas basados en estándares de desarrollo aplican fundamentalmente evaluación formativa, tal como la conciben los profesores. En cambio, aquellos sistemas basados en evaluaciones competitivas tienden a hacer uso de la evaluación sumativa. Lo anterior, explica la representación negativa que los docentes tienen del uso de la certificación docente para la obtención de mejoras salariales.

Algunas razones para resistirse a la evaluación propuesta, se vinculan a la complejidad del ejercicio docente que obstaculiza la modificación de las prácticas y a la invisibilización de factores externos a la escuela y a la docencia que inciden en los resultados de aprendizaje. Algunas investigaciones (Barber y Mourshed, 2008; Belleï y Valenzuela, 2010; Schmelkes, 2014), confirman que los factores con mayor incidencia en el aprendizaje son el origen social, económico y cultural de los estudiantes. Por tanto, si se evalúa el desempeño docente se deberían tener en cuenta las condiciones del contexto y sus implicancias en el ejercicio profesional. Schmelkes (2014), agrega que cuando las políticas docentes se diseñan en forma unilateral al nivel de la superestructura, se producirá una débil conexión entre los administradores y los docentes.

Desde esta perspectiva, una propuesta de carrera profesional legítima debiera considerar la existencia de sistemas de evaluación que contemplen diversos factores e instrumentos cuya información debe triangularse para obtener una visión más holística del desempeño docente. Schmelkes (2014, p. 171) afirma que "existe un amplio consenso en que es preferible evaluar a los maestros por su práctica (una 'buena enseñanza') en lugar de por su desempeño (una 'enseñanza exitosa')". En definitiva, los parámetros de lo que se entiende por una buena enseñanza debieran ser definidos con participación de los propios profesores.

En relación con las representaciones de los profesores sobre sus condiciones de trabajo, se confirma lo planteado por Ávalos et al. (2010, p. 237) respecto de que "las políticas educativas parecen fundarse más en el temor a la incapacidad de los docentes para manejar las demandas de la nueva sociedad que en apoyar su trabajo". Coincidimos con Mejía (2010), quien plantea que las concepciones de la profesión docente en Latinoamérica están siendo afectadas por: 
1. la "despedagogización" que alude a la jibarización del proceso pedagógico reduciéndolo a meras "técnicas";

2. la "desprofesionalización", entendida como la preeminencia de criterios de productividad para medir la eficacia-eficiencia y determinar su rendimiento; $y$

3. la "pauperización" que encuentra expresión en distintas dimensiones como la económica/salarial, la social (desvalorización social de la docencia), la ideológica (pérdida del sentido social del oficio docente) y la personal (aumento de los fenómenos de sufrimiento y malestar en los docentes). Toda esta representación social se puede observar nítidamente en los relatos como categorías textuales y como estructuras de relaciones.

Las representaciones de los profesores sobre las condiciones laborales del ejercicio de la profesión coinciden con Belleï y Valenzuela (2010), quienes plantean que existe una regulación contractual asimétrica dependiendo de si el empleador (sostenedor) pertenece al sector público o privado. Esta asimetría determina condiciones de trabajo muy diferentes para quienes se desempeñan en uno $u$ otro sector e incentiva una segmentación de los docentes de acuerdo al tipo de sostenedor y de acuerdo a la edad de los profesores, a pesar de que ambos sectores reciban el mismo subsidio estatal para contratar docentes. A esto se agrega los bajos salarios de los profesores. Según la OCDE (2014a), los docentes chilenos con quince años de experiencia ganan sueldos un 39\% más bajo que el promedio de los países de la organización. Belleï y Valenzuela (2010, p. 270) concluyen que "el verdadero grupo de comparación de los docentes en términos de sus salarios son quienes estudian carreras técnicas".

La literatura reporta también, que la proporción entre horas lectivas y no lectivas afecta las condiciones laborales docentes. El último Estudio Internacional sobre la Enseñanza y el Aprendizaje (OECD, 2014a, 2014b, 2014c), indica que la relación horas de aula/horas de trabajo para los profesores chilenos de educación media es de 92\%-98\%, muy superior a la proporción 50\%-50\% en el promedio de los países de la OCDE. En educación básica la carga de trabajo docente sobrepasa las 1.103 horas anuales en aula, mientras en el promedio de los países OCDE llega a 782 horas. Adicionalmente, el elevado número de alumnos por curso afecta el trabajo docente en el aula, según OCDE (2014a), el promedio de alumnos por aula en Chile es 30 , mientras que el promedio de los países miembros de la organización es de solo 22.

Por último, la representación de los profesores sobre las políticas nacionales de formación inicial y continua confirma los planteamientos de Vaillant y Marcelo (2015). En efecto, se plantea el rol clave de políticas que incentiven el ingreso de estudiantes talentosos a estudiar pedagogía. Una formación inicial de calidad puede mantener a los docentes en la profesión (Barber y Mourshed, 2008; OECD, 2014), considerando que según UNESCO (2013), la vida profesional de un docente alcanza de treinta a cuarenta años de ejercicio. Si las investigaciones indican que el ejercicio docente muestra cambios significativos según la etapa en la vida profesional, las propuestas de carrera profesional docente debieran abordar cada etapa como parte de la trayectoria (Day et al., 2006; Marcelo, 2010; Vaillant, 2009). 


\section{CONCLUSIONES}

Para el análisis de la política educativa hemos utilizado las categorías analíticas planteadas por Grindle (2001) respecto de estructura, acción y proceso y hemos añadido lo planteado por Weinstein (2014) sobre las instituciones (insertas en la estructura), distinguiendo entre aquellas "decisoras" e "influenciadoras". La Figura 3, muestra que en las representaciones sociales de los profesores se incluye la interacción dinámica entre estos componentes.

En efecto, en la "estructura" nos podemos explicar la oposición al proyecto como producto de la invisibilización del Colegio de Profesores como institución "decisora" (en palabras de Weinstein, 2014) y su consideración sólo como una entidad más dentro de las instituciones "influenciadoras". Entonces, y siguiendo los planteamientos de Grindle (2001), un camino posible para que esta reforma progrese sería la inclusión del Colegio de Profesores como entidad decisora y sumar otras instituciones influenciadoras como las recomendaciones hechas por organismos internacionales y centros de estudio especializados.

Para que esto ocurra, debe introducirse el concepto de agencia (Grindle, 2001), es decir, acciones o intervenciones que pueden producir cambios en las condicionantes que generan hostilidad hacia el proyecto y la férrea oposición al mismo. En este sentido, postulamos la legitimidad de la movilización social realizada por el Colegio de Profesores, la apertura de un debate público amplio, la consideración a la opinión de expertos y el debate parlamentario.

Finalmente, respecto del proceso, es preciso entender esta categoría analítica como una llave que abre o cierra posibilidades de producir quiebres o cambios en las "estructuras" y nos remite a la idea de que toda reforma es un proceso. Aplicando el concepto de proceso, debemos asumir que la co-construcción de un nuevo y reno-

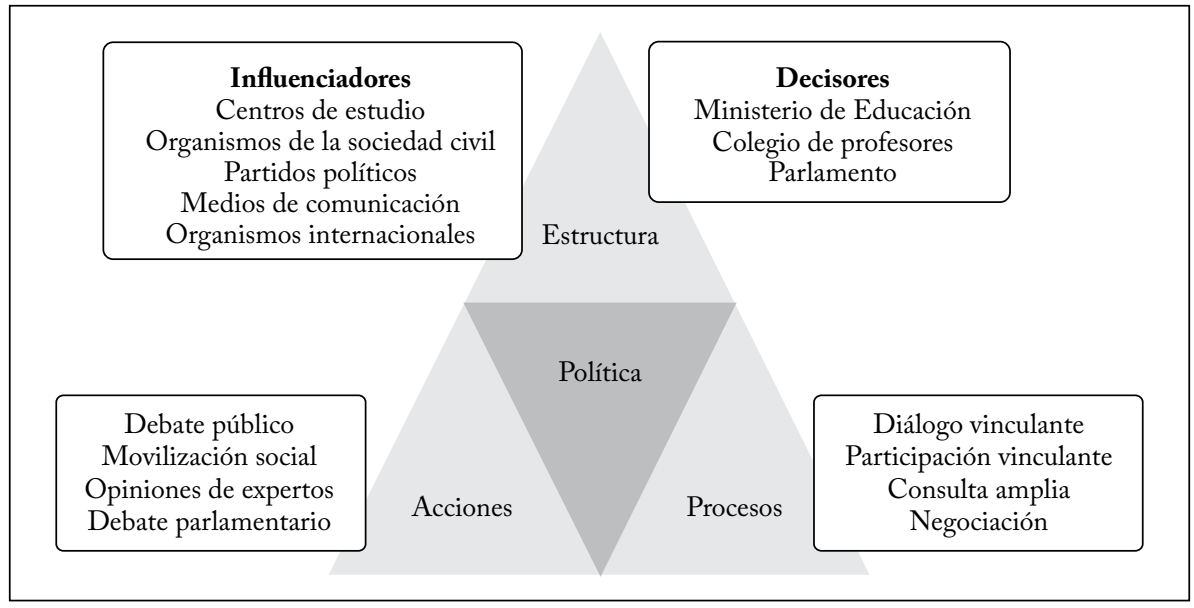

Figura 3 - Elementos de análisis para una política educativa.

Fonte: Base de datos de búsqueda.

Elaboración propia. 
vado Proyecto de Carrera Profesional Docente se hace totalmente necesaria toda vez que, en el nuevo ciclo de la política - entendida como acción pública — que se levanta en los años 2000, es imprescindible sumar actores y grupos de interés en la reforma. Aparecen ineludibles, por tanto, procesos de diálogo, de participación vinculante, de negociación, para conseguir materializar uno de los eslabones claves en una reforma educativa que aspira a cambiarle la cara a la educación chilena: una nueva carrera profesional docente, como una reforma representativa, legítima, co-construida y aceptada por los actores relevantes y la sociedad en su conjunto.

\section{REFERENCIAS}

Ávalos, B.; Cavada, P.; Pardo, M.; Sotomayor, C. La profesión docente: temas y discusiones en la literatura internacional. Estudios Pedagógicos, Valdivia: Universidad Austral de Chile, v. 36, n. 1, p. 235-263,2010. DOI: http://dx.doi.org/10.4067/S071807052010000100013

Ávalos, B.; Sotomayor, C. Cómo ven su identidad los docentes chilenos. Perspectiva Educacional, Viña del Mar: Pontificia Universidad Católica de Valparaíso, v. 51, n. 1, p. 57-86, 2012. DOI: http://dx.doi.org/10.4151/07189729-Vol.51-Iss.1-Art.74

Barber, M.; Mourshed, M. Cómo hicieron los sistemas educativos con mejor desempeño del mundo para alcanzar sus objetivos. Buenos Aires: McKinsey \& Company; PREAL, v. 41,2008. Disponible en: <http://www.oei.es/pdfs/documento_preal41.pdf $>$. Acceso en: 2 ago. 2018.

BeCA, C. La profesión docente en Chile y el debate sobre una nueva carrera profesional. Revista Docencia, Santiago de Chile: Colegio de Profesores de Chile A.G., v. 54, p. 4-17, 2014. Disponible en: <http://revistadocencia.cl/ revist37/web/images/ediciones/ Docencia_54.pdf>. Acceso en: 2 ago. 2018.

Belleï, C.; Valenzuela, J. P. ¿Están las condiciones para que la docencia sea una profesión de alto estatus en Chile? In: Martinic, S.; Elacoua, G. (Eds.). í Fin de ciclo? Cambios en la gobernanza del sistema educativo. Santiago de Chile: OREALC; UNESCO; Pontificia Universidad Católica de Chile, 2010. p. 257-283. Disponible en: <http://unesdoc.unesco.org/images/0019/001905/190544S.pdf〉. Acceso en: 2 ago. 2018.

Chile. Presidencia de la República. Proyecto que crea el sistema de desarrollo profesional docente y modifica otras normas. Santiago: Presidencia de la República, 20 abr. 2015.

Day, C.; Stobart, G.; Sammons, P.; Kington, A.; Gu, Q.; Smees, R.; Mujtaba, T. Variations in teachers' work, lives and effectiveness (Research Report). Londres: University of Nottingham; London Institute of Education, 2006. Disponible en: <http://dera.ioe. ac.uk/6405/1/rr743.pdf>. Acceso en: 2 ago. 2018.

FARr, R. M. Social representations. Cambridge: University Press, 1984.

Greimas, A.J. Semántica estructural: investigación metodológica. Madrid: Gredos, 1987.

GRINDLE, M. La paradoja de la reforma educacional: pronosticar el fracaso y encontrar el progreso. In: Martinic, S.; PARdo, M. (Eds.). "La economía politica de las reformas 
educativas en América Latina". Santiago, Chile, PREAL; CIDE, 2001. p. 15-60. Disponible en: <http://cippec.org/mapeal/wp-content/uploads/2014/06/MARTINICy-PARDO-Econom\%C3\%ADa-pol\%C3\%ADtica-de-las-reformas-educativas-enAmLat.pdf >. Acceso en: 2 ago. 2018.

Jobert, B.; Muller, P. L'Etat en action: politique publiques et corporatismes. París: Presses Universitaires de France, 1987. Disponible en: <https://hal.archives-ouvertes. fr/file/index/docid/137940/filename/B_Jobert_L_Etat_en_action.pdf $>$. Acceso en: 2 ago. 2018.

Jodelet, D. La representación social: fenómenos, concepto y teoría. In: Moscovici, S. (Comp.). Psicología social II. Barcelona: Paidós, 1986. p. 469-493.

Marcelo, C. Políticas de inserción a la docencia: de eslabón perdido a puente para el desarrollo profesional docente. In: El profesorado principiante: inserción a la docencia. Barcelona: Octaedro, 2010. p. 7-58.

Martinic, S. Análisis estructural: presentación de un método para el estudio de lógicas culturales. Santiago: Centro de Investigación y Desarrollo de la Educación, 1992. Disponible en: <http://repositorio.uahurtado.cl/handle/11242/8291>. Acceso en: 2 ago. 2018.

. El objeto de la sistematización y sus relaciones con la evaluación y la investigación. In: Seminario Latinoamericano: Sistematización de PRÁcticas de animación sociocultural y participación ciudadana en América Latina. Medellín: Fundación Universitaria Luis Amigó; CEAAL, agosto 1998. p. 12-14. Disponible en: <http://centroderecursos.alboan.org/ebooks/0000/0748/6_CEA_OBJ.pdf>. Acceso en: 2 ago. 2018.

. Cambios en las regulaciones del sistema educativo. ¿Hacia un Estado evaluador? In: Martinic, S.; Elacoua, G. (Eds.). i Fin de ciclo? Cambios en la gobernanza del sistema educativo (p. 55-78). Santiago de Chile: OREALC; UNESCO; Pontificia Universidad Católica de Chile, 2010.p. 55-78. Disponible en: <http://unesdoc.unesco. org/images/0019/001905/190544S.pdf>. Acceso en: 2 ago. 2018.

Martinic, S.; Elacqua, G. (Eds.). educativo. Santiago de Chile: OREALC; UNESCO; Pontificia Universidad Católica de Chile,2010. Disponible en: <http://unesdoc.unesco.org/images/0019/001905/190544S. pdf $>$. Acceso en: 2 ago. 2018.

Mejía, M. R. Las pedagogías críticas en tiempos de capitalismo cognitivo. Revista Aletheia, Bogota: CINDE, v. 2, n. 2, p. 58-101, 2010. Disponible en: <http://aletheia. cinde.org.co/index.php/ALETHEIA/article/view/27/24>. Acceso en: 2 ago. 2018.

Miles, M. B.; Huberman, A. M. Analyse des données qualitatives. París: De Boeck Université, 2003.

Ministerio de Educación. Aprueba reglamento de la ley n. 19.070. Estatuto de los Profesionales de la Educación. Santiago: Presidencia de la República, 26 nov. 1991.

. Establece ley de subvención escolar preferencial. Santiago: Presidencia de la República, 25 jan. 2008.

. Establece la Ley General de Educación. Santiago: Presidencia de la República, 17 ago. 2009a. 
. Modifica decreto supremo n. 40 de 1996, del Ministerio de Educación, que establece los objetivos fundamentales y contenidos minimos obligatorios de la educación básica y fija normas generales para su aplicación. Santiago: Presidencia de la República 18 ago. 2009b. . Establece bases curriculares para la educación básica en asignaturas que indica. Santiago: Presidencia de la República 23 dez. 2011.

. Establece las direcciones regionales de la superintendencia de educación y oficinas regionales de la Agencia de Calidad de la Educación y define sus potestades, funciones y el ámbito geográfico que abarca cada una de ellas. Santiago: Presidencia de la República, 15 jun. 2012.

Montecinos, C. Análisis crítico de las medidas de presión propuestas para mejorar la formación inicial de docentes en Chile por el Panel de Expertos para una Educación de Calidad. Estudios Pedagógicos, Valdivia: Universidad Austral de Chile, v. 40, número especial, p.285-301,2014. DOI: http://dx.doi.org/10.4067/S0718-07052014000200017 Moscovici, S. The history and actuality of social representations. In: FLICK, U. (Ed.). The Psychology of the Social. Cambridge: University Press, 1998. p. 209-220.

OECD - Organización para la Cooperación y el Desarrollo Económicos. Talis 2013: Estudio Internacional de la Enseñanza y el Aprendizaje. Educainee, Madrid: Instituto Nacional de Evaluación Educativa, 34, p. 1-4, 2014a.

. Guía del profesorado. TALIS 2013: Estudio Internacional sobre Enseñanza y Aprendizaje. [S.1.]: OECD Publishing, 2014b.

. TALIS 2013 results: an international perspective on teaching and learning. [S.1.]: OECD Publishing, 2014c.

Schmelkes, S. La evaluación del desempeño docente: estado de la cuestión. In: UNESCO - Organización de las Naciones Unidas para la Educación, la Ciencia y la Cultura. Temas críticos para formular nuevas politicas docentes en América Latina y el Caribe. Santiago de Chile: OREALC; UNESCO, 2014. p. 154-185.

UNESCO - Organización de las Naciones Unidas para la Educación, la Ciencia y la Cultura. Temas críticos para la elaboración de politicas docentes en América Latina y el Caribe. Santiago de Chile: OREALC; UNESCO, 2013.

Vaillant, D. Políticas de inserción a la docencia en América Latina: la deuda pendiente. Profesorado - Revista de Curriculum y Formación del Profesorado, Granada: Universidad de Granada, v. 13, n. 1, p. 27-41, 2009.

Vaillant, D.; Marcelo, C. El ABCy D de la formación docente. Narcea Ediciones, 2015. VANNI, X.; Bravo, J. En búsqueda de una educación de calidad para todos. El sistema nacional de aseguramiento de la calidad. In: Martinic, S.; Elacqua, G. (Eds.). $\dot{\zeta}$ Fin de ciclo? Cambios en la gobernanza del sistema educativo. Santiago de Chile: OREAL; UNESCO; Pontificia Universidad Católica de Chile, 2010. p. 183-205.

Wagner, W.; Moscovici, S.; Hayes, N.; Flores Palacios, F. El discurso de lo cotidiano y el sentido común la teoría de las representaciones sociales. Rubí, Barcelona: Anthropos, Editorial, 2011. 
Weinstein, J. La esquiva política entre las volátiles políticas docentes. In: UNESCO Organización de las Naciones Unidas para la Educación, la Ciencia y la Cultura. Temas críticos para la elaboración de políticas docentes en América Latina y el Caribe. Santiago de Chile: OREALC; UNESCO, 2014.

\section{SOBRE LAS AUTORAS}

María Teresa Castañeda Díaz es doctora en ciencias de la educación por la Universidad de La Frontera (Chile). Profesora de la Universidad del BíoBío (Chile).

E-mail:mcastane@ubiobio.cl

Carmen Gloria Jarpa Arriagada es doctora en ciencias de la educación por la Universidad de La Frontera (Chile). Profesora de la Universidad del BíoBío (Chile).

E-mail: cjarpa@ubiobio.cl 